\title{
Fuzzy Logic Control Application for the Prototype of Gun-Turret System (ARSU 57 mm) Using Matlab
}

\author{
Munadi, Joga Dharma Setiawan, and Muhammad Fairuz Luthfa
}

\begin{abstract}
In this work, we study the problem of gun-turret control. High precision control is desirable for future weapon systems. Several control design strategy are applied to a weapon system to assess the applicability of each control design method and to characterize the achievable performance of the gun-turret system in precision control. The gun-turret control is achieved through proper combined actuation of its azimuth and elevation inputs, which ARSU $57 \mathrm{~mm}$ is one of gun-turret system was manually driven by human power. We modify to make a prototype of ARSU $57 \mathrm{~mm}$ using two DC motors as actuator for controlling the angle of azimuth rotation and elevation mavement of barrel. The proportional integral derivative (PID) and fuzzy logic control will be proposed for controlling this gun-turret system. The control design objective of the gun-turret control system is to achieve a rapid and precise tracking response with respect to the turret motor command and the barrel motor command. We apply hardware in the loop (HIL) as a technique that is used in the development and test of both control methods. The PID control is implemented to avoid overshooting and high-frequency oscillations. The fuzzy logic control is provided as an effective means of capturing the approximate, to address unexpected parameter variations without mathematical equations. Matlab/Simulink and fuzzy logic toolbox is used to set up the application of the gun-turret system. Experimental results are presented to show the performance of the controller.
\end{abstract}

Index Terms-Gun-turret system, ARSU 57 mm, fuzzy logic control.

\section{INTRODUCTION}

Tools armament has an important role for the national security of a country. Therefore, the independence of armament equipment is a major key in protecting their territory. Indonesia, which has one of the islands in the world that has a fairly wide geographical area in need of defense and security, especially defense equipment to protect its territory. Of course the cost required for the purchase of defense equipment is quite high, for that Indonesia needs to develop and produce its own armaments system that is independent of the other countries.

ARSU $57 \mathrm{~mm}$ cannon which is the gun-turret system is one of the major parts in weapons systems the Army and Navy, which is where it comes out of the barrel cannon projectiles

Manuscript received December 20, 2013; revised February 28, 2014. This work was supported Implementing Indonesia's Economic Master Plan (MPEI) that supported by grand number: 253/SP2H/PL/DIT.LITABMAS/VII/2013.

Munadi and Joga D. S. are with the Dept. of Mechanical Engineering, Diponerogo University, Indonesia (e-mail: munadi@undip.ac.id, jsetiawan@undip.ac.id).

Muhammad F. L. is with the Electrical Engineering Department in Diponegoro University, Indonesia. were fired. ARSU $57 \mathrm{~mm}$ cannon still manually driven by human power in the rotating and directing the elevation of the barrel when facing the direction of the target. In operation of ARSU $57 \mathrm{~mm}$ is still done by turning the crank shaft to move the position of the azimuth and elevation angle of the cannon barrel. Because it is done manually, it can change parameters for each operator which can cause non-linearities motion position angle of the cannon. Therefore, an efficient control strategy must be employed to ensure precision position tracking control, such as variable-structure control by Hung et $a l$. [1] and hybrid adaptiveand learning control by Munadi et al. [2].

It is worth note that the field of gun-turret system is very sensitive to defense industry and establishment and not much detail and complete have been reported or published in the literature that discusses the control strategy of weapon system. The following references is published that discuss the weapons control systems. Feng et al. [3] used sliding mode control combined with adaptive fuzzy control for control system of tank. Lewis et al. [4] treated the gun turret assembly for a tank control system as a-co link robot arm. Kumar et. al. [5] proposed a model predictive control to expand a control strategy developed for such a system must avoid possible collision of the gun/turret system with obstacles. Gomes et al. [6] developed a fully coupled dynamic model for proposing a feedback linierization control scheme.

Further, Zadeh [7] proposed a fuzzy logic which is one of intelligent control techniques. Originally advocated by Zadeh, fuzzy logic has become a means of collecting human knowledge and experience and dealing with uncertainies in the control process, it is explained by Mamdani [8]. This control method is applied for controller design in many applications which is becoming a very popular topic in control engineering, such as presented by Das et al. [9]. This control strategy is by far the most useful application of fuzzy logic theory, also its successful applications to variety of consumer products such as for a washing machine [10] and industrial systems have helped to attact growing attention and interest, including in weapon system area. One application of fuzzy logic control of gun-turret system is developed by Kim et al. [11], and Galal et al. [12] have showed that fuzzy logic can reduce the effects of nonlinearity in a DC motor and improve the performance of a controller used DC motor, and Mrozek et al. [13] presented a modelling and fuzzy control of DC motor.

Based on its design simplicity of fuzzy logic control, in this paper, we implement a fuzzy logic control for position control of prototype of ARSU $57 \mathrm{~mm}$ which is driven by DC motor. We show that fuzzy logic control can be used asan effective control strategy for azimuth rotation of base and elevation 
movement of barrel of ARSU $57 \mathrm{~mm}$. For the paper layout, in Section II, we describe the system description of ARSU 57 $\mathrm{mm}$. In Section III, the controller design are discussed, including the fuzzy logic control is develoved and discussed in detail. Performance comparations between the PID and fuzzy logic control are given in Section IV which demonstrate the efficiency of controller. Finally the conclutions drawn from the experimental results obtained are given in Section V.

\section{SISTEM DESCRIPTION}

The first step in our research is designing a prototype of ARSU $57 \mathrm{~mm}$ using a CAD software. The prototype is designed with scale 1:5 of the original gun-turret system (ARSU $57 \mathrm{~mm}$ ). The original gun-turret system is shown in Fig. 1.

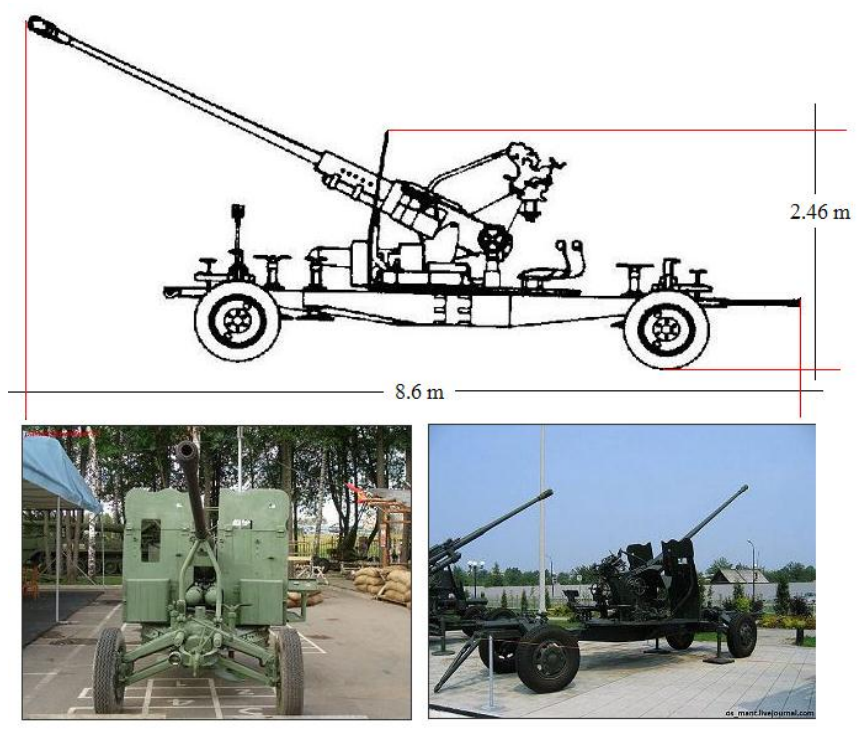

Fig. 1. ARSU $57 \mathrm{~mm}$.

Then, Fig. 2 depicts the components of prototype gun-turret, and Fig. 3 shows the prototype of gun-turret system where the most of material is used in the manufacture from acrylic. The prototype of gun-turret system consists of two revolute joints with two electric DC motors at each joint. The first joint describes azimut rotation that uses a DC motor, whereas the second joint drives an elevation movement of barrel, in which it uses DC motor also.
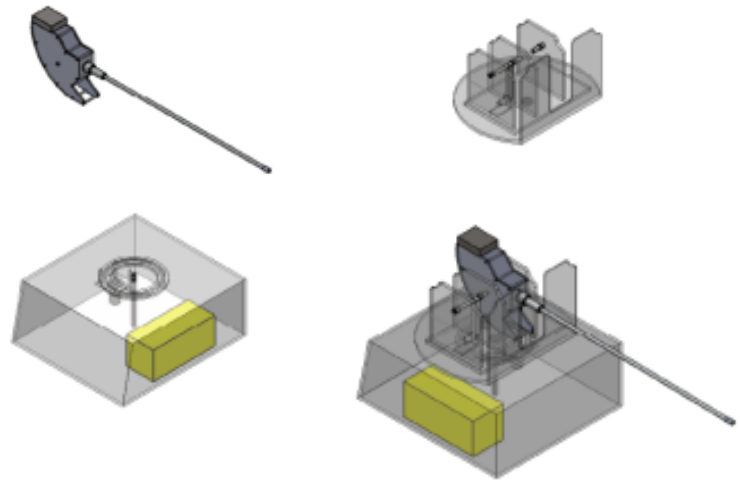

Fig. 2. Components of prototype of ARSU $57 \mathrm{~mm}$.
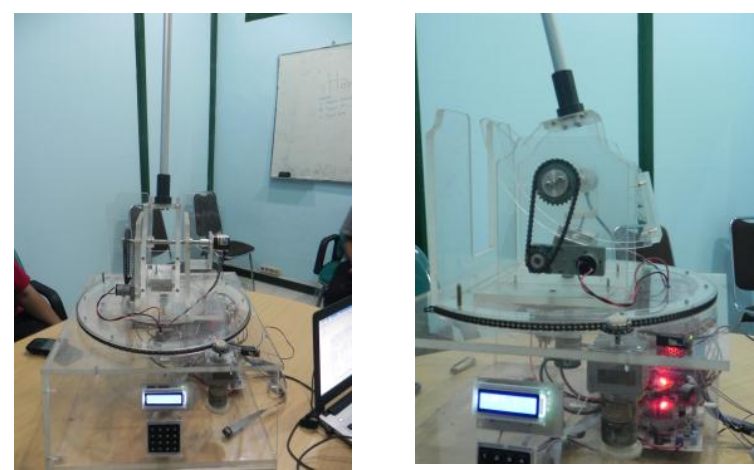

Fig. 3. Prototype of ARSU $57 \mathrm{~mm}$

The electric components of prototype of gun-turret consist of microcontroller, power supply, DC motor, DC motor driver, encoder, and laptop. In detail, the relationship of each component is shown in Fig. 4.

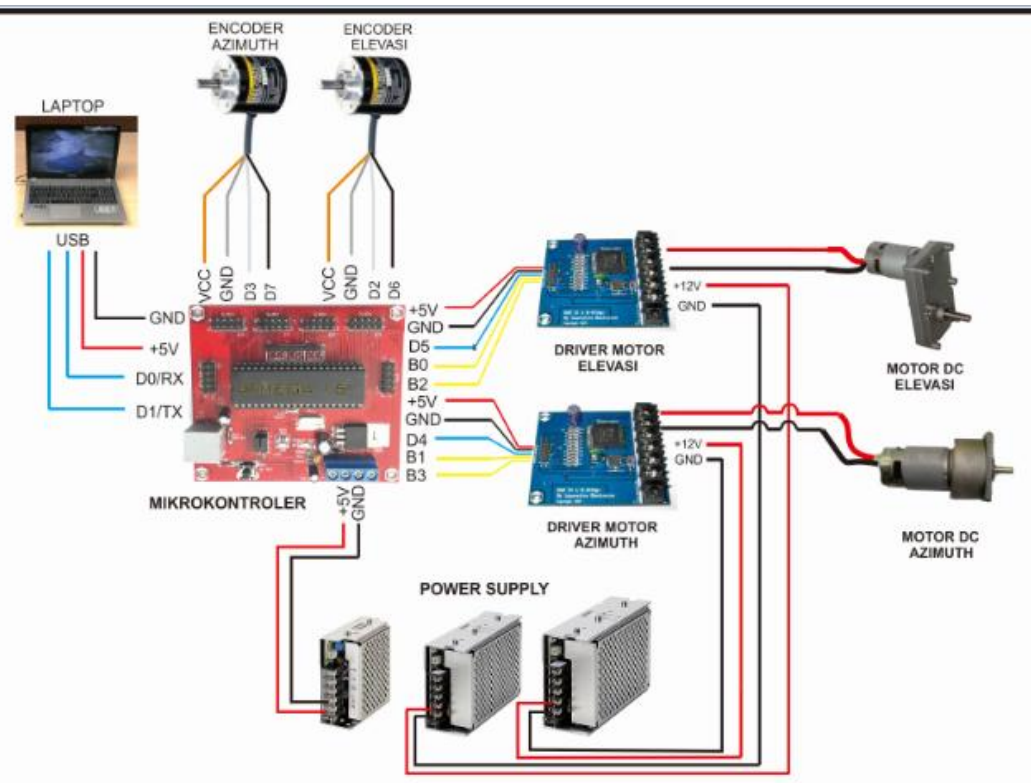

Fig. 4. Electric component of prototype of gun-turret. 


\section{CONTROLLER DESIGN}

In this work, we show the design for the implementation of two control strategy through hardware in the loop: one based on proportional integral derivative (PID) controller, and another based on fuzzy logic controller. Two controller (PID and fuzzy logic) will be investigated carefully.

\section{A. PID Controller}

PID control is a feedback control scheme widely used in engineering, science, and industry. The popularity of PID is largely due to its ease of implementation and effectiveness. Motivation for the use of PID stems from its accuracy: a PID controller is never an optimum controller but is good enough in most cases to increase in position tracking performance, including in the gun-turret systems. The controller design of PID controller for prototype of gun-turret is shown in Fig. 5. We implement PID controller uses Matlab/simulink which contains two mode of a degree input that is shown by a manual switch. All tollboxs can drag that are available in Simmulink toolbox.

In Simulink model, we define two PID controller. The first controller is defined for controlling an azimuth rotation of base of gun-turret that is shown in Fig. 6 (a), and the second controller is prescribed an elevation movement of barrel that is shown in Fig. 7 (a).

\section{Azimuth Control}

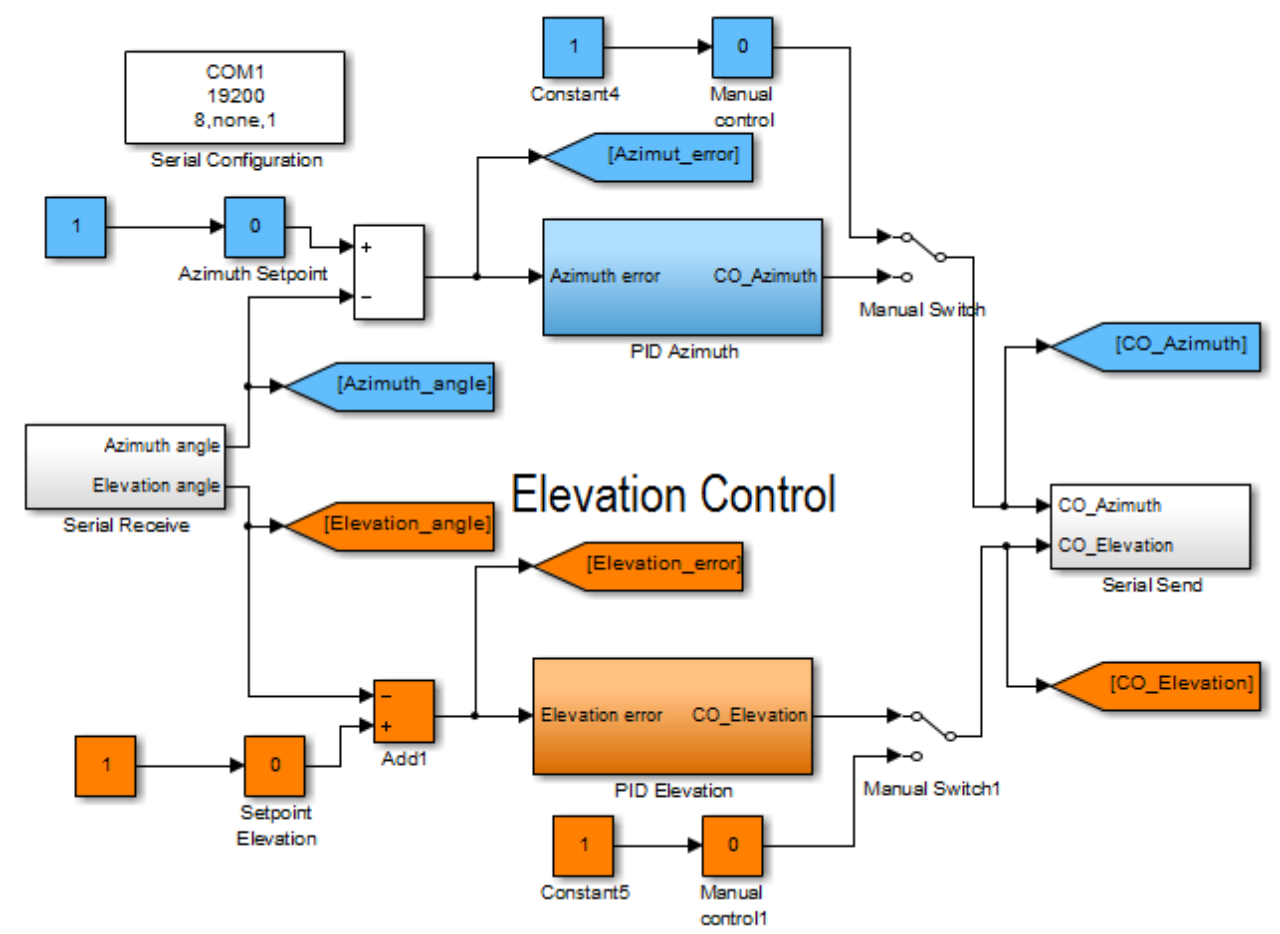

Fig. 5. Simulink model for PID controller.

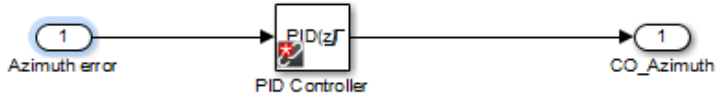

(a) PID controller block for azimuth

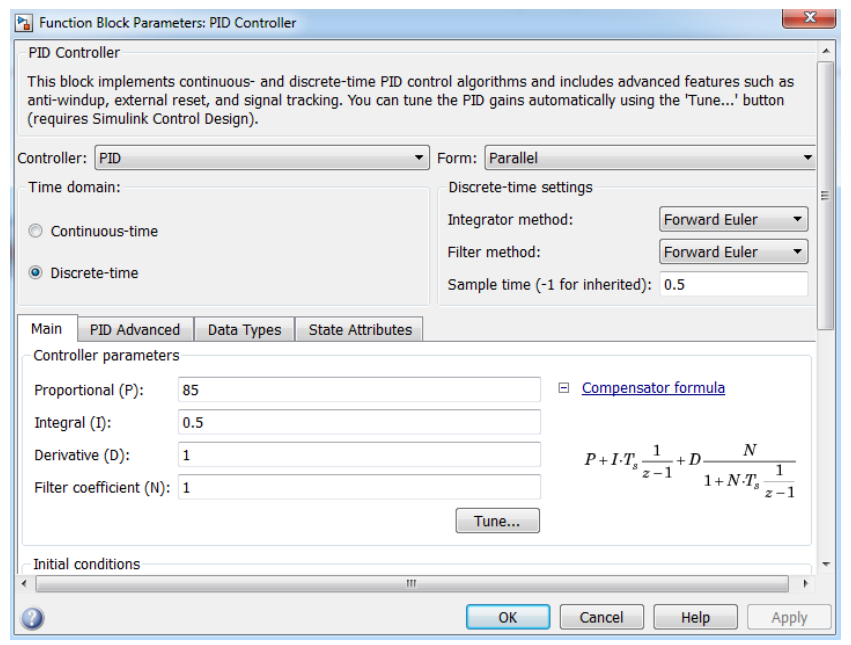

(b) Fuction block parameter for azimuth

Fig. 6. PID controller for azimuth rotation.
Further, the biggest problem of the PID controller design is PID tuning, which determines the gain value of $\mathrm{Kp}, \mathrm{Ki}$, and $\mathrm{Kd}$. As long as the model of plant/system is defined, the PID tunning methods are performed based on the mathematical model of plant/system. But if the model of plant is not known, then the PID turning is performed based on the experiments of system. There are several prescriptive rules used in PID tuning. One of PID tuning methods is the Ziegler-Nichols tuning method that was proposed by John G. Ziegler and Nataniel B. Nichols. This tuning method is performed by setting the integral and derivative gains to zero. The proportional gain $(\mathrm{Kp})$ is then increased (from zero) until it reaches the ultimate gain $(\mathrm{Ku})$, at which the output of the control loop oscillates with a constant amplitude. $\mathrm{Ku}$ and the oscillation period $\mathrm{Tu}$ are used to set the $\mathrm{P}, \mathrm{I}$, and $\mathrm{D}$ gains. For simulation on simulink, we use this Ziegler-Nichols tuning method to define PID gain value, but in the experiments, we directly use the tuning menu is on the function block parameter that is shown in Fig. 6 (b) for azimuth rotation and Fig. 7 (b) for elevation movement. 


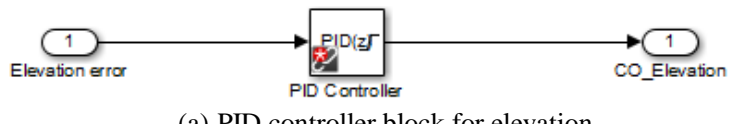

(a) PID controller block for elevation

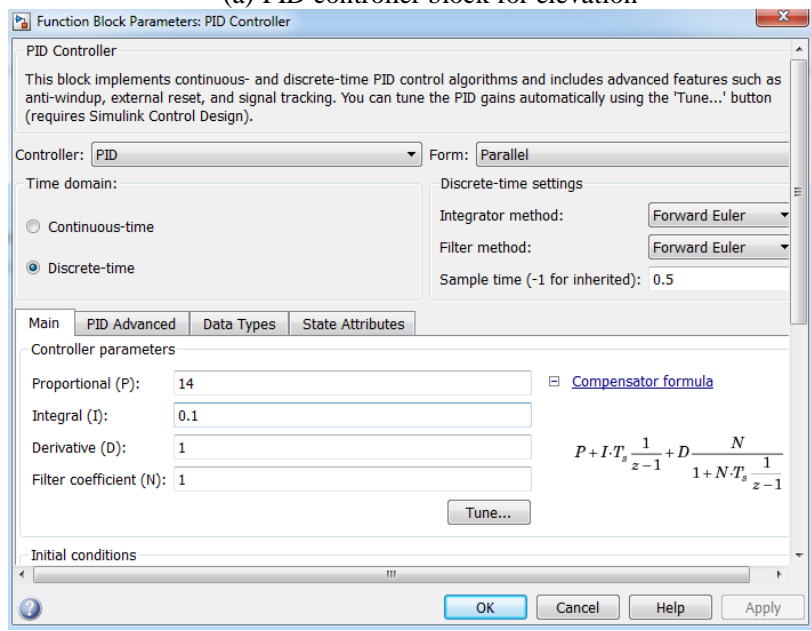

(b) Fuction block parameter for elevation

Fig. 7. PID controller for elevation movement of barrel.

\section{B. Fuzzy Logic Controller}

The fuzzy logic is being used in many engineering applications because it is considered by designers to be the simplest solution available for the specific problem without a lot of mathematical equations that is involved. The fuzzy logic allows computers to reason more like humans, responding effectively to complex inputs to deal with linguistic notations. Other advantages of fuzzy logic is that this controller can be easily upgraded by adding new rules to improve performance or add new features.

For applicating the fuzzy logic control in the prototype of gun-turret, we use fuzzy logic toolbox on Matlab/simulink. The step process for fuzzy logic control are divided into three procedure that are; defining linguistic inputs, defining fuzzy controller itself, and defining output. Defining the inputs and outputs are done in FIS editor that is shown in Fig. 8. The inputs are the error between the reference angle and the actual angle of azimuth rotation that is obtaned based on the sensor (encoder).

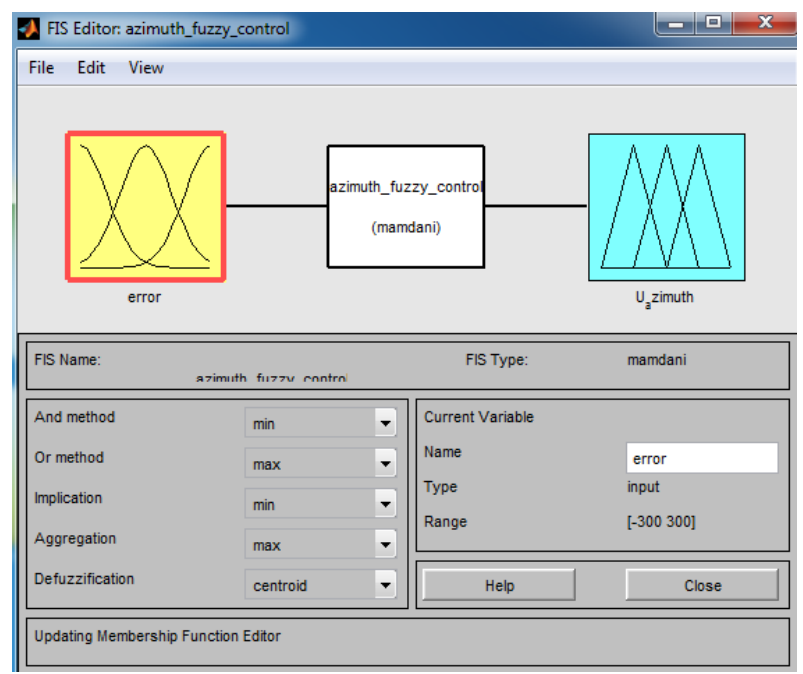

Fig. 8. FIS editor for azimuth control.

The next step is defining the fuzzy logic controller itself which is consist of fuzzyfication, fuzzy arithmetic and applying criterion, and defuzzyfication. In this step, we define fuzzy membership functions and rules by converting the inputs and outputs from numerical value into linguistic forms. We define seven fuzzy variables as shown in Table I.

TABLE I: SEVEN FUZZY VARIABLES

\begin{tabular}{|c|c|c|c|c|c|c|}
\hline VS & S & RS & M & RL & L & VL \\
\hline Very & Small & $\begin{array}{l}\text { Rather } \\
\text { Small }\end{array}$ & Medium & $\begin{array}{c}\text { Rather } \\
\text { Large }\end{array}$ & Large & $\begin{array}{c}\text { Very } \\
\text { Large }\end{array}$ \\
\hline
\end{tabular}

Further, we choose trapezoidal shapes that are easy to represent idea and require low computation time for definining the fuzzy membership function. It is shown by Fig. 9 , specially in right bottom side.

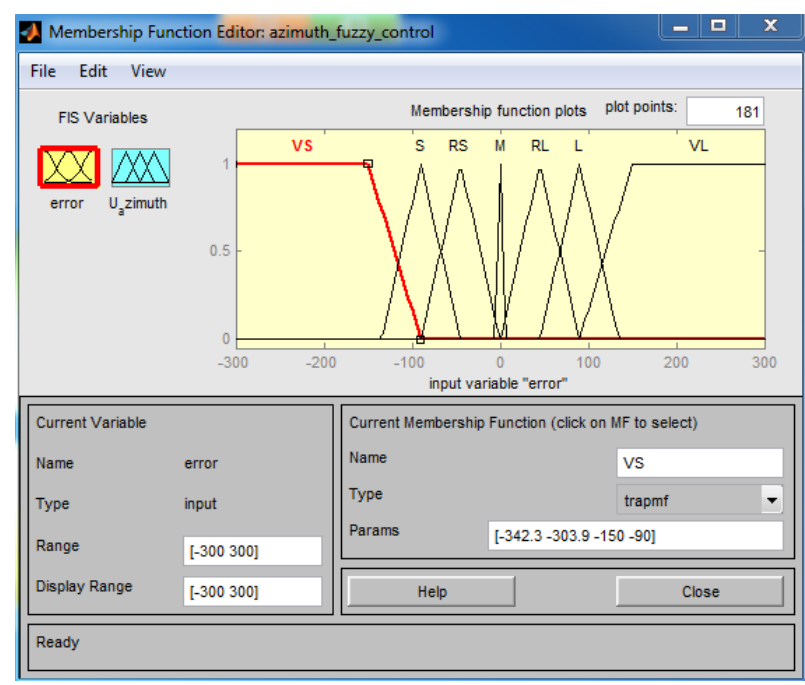

Fig. 9. Membership function editor for azimuth control.

For the next step, we have to define the sets of rules used to derive the output, and they are:

1) If (error is VS) then (U_azimuth is VS)

2) If (error is $S$ ) then (U_azimuth is $S$ )

3) If (error is RS) then (U_azimuth is RS)

4) If (error is M) then (U_azimuth is M)

5) If (error is RL) then (U_azimuth is RL)

6) If (error is L) then (U_azimuth is L)

7) If (error is VL) then (U_azimuth is VL)

The above rules definition is shown in Fig. 10. For all above explanation of fuzzy logic control are steps that is used to control the azimuth rotation of gun-turret system. Whereas for elevation control, the similar procedure is applied to find the azimuth rotation control.

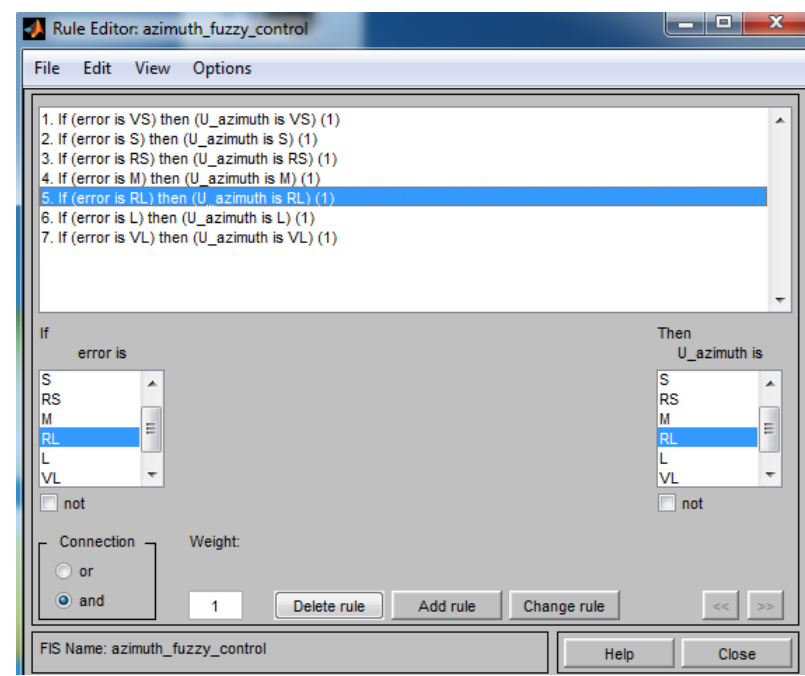

Fig. 10. Rule editor for azimuth control. 
Hereinafter, the simulink model of fuzzy logic control is shown in Fig. 11 which is developed by using fuzzy logic toolbox in Matlab. Based on fuzzy logic toolbox, we use and drag several blocks, such as setpoint block, sink block, and fuzzy controller block.

\section{Azimuth Control}

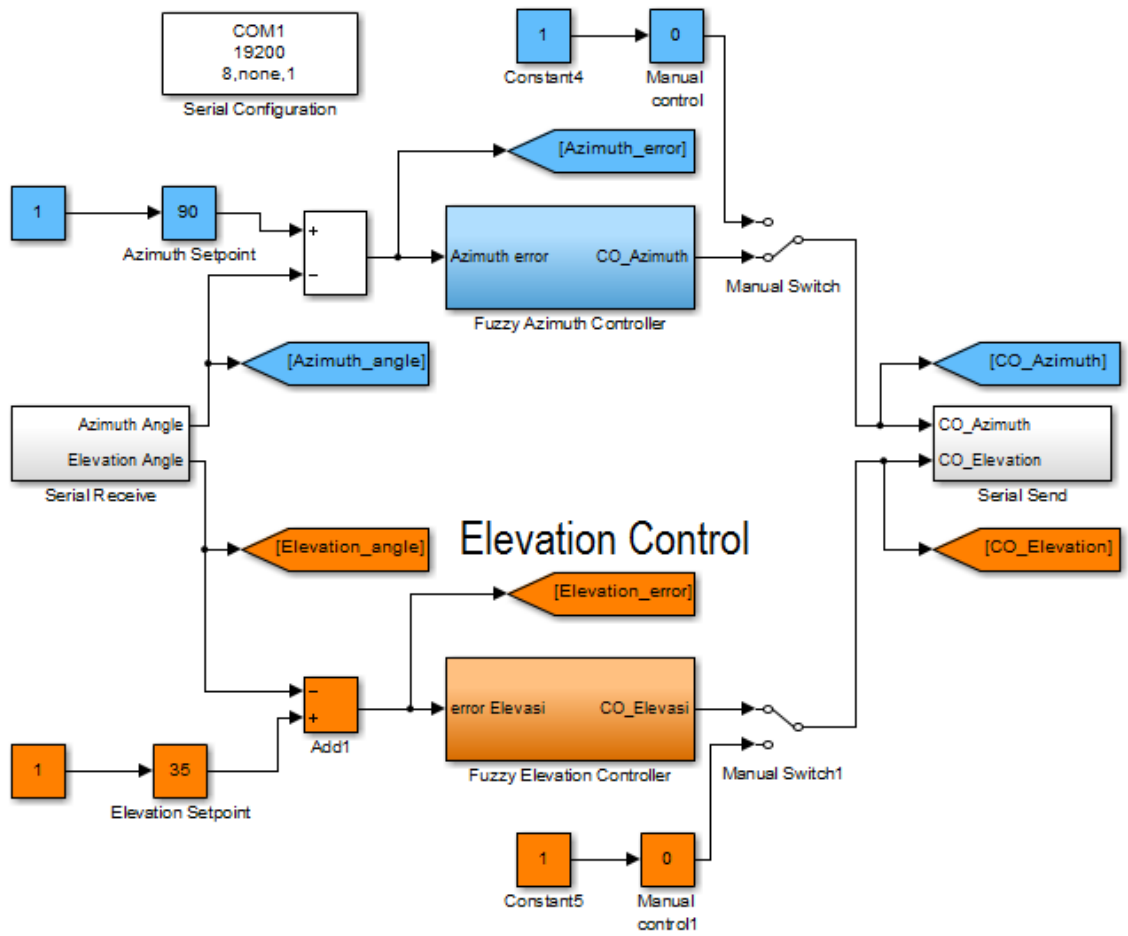

Fig. 11. Simulink model for fuzzy logic controller.

In Simulink model, we define a fuzzy logic control with rule viewer that is shown in Fig. 12 (a), and (b) describes a function block parameter that is be filled by FIS file that we created out first.

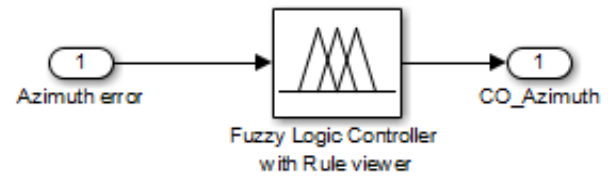

(a) Fuzzy logic controller with rule viewer

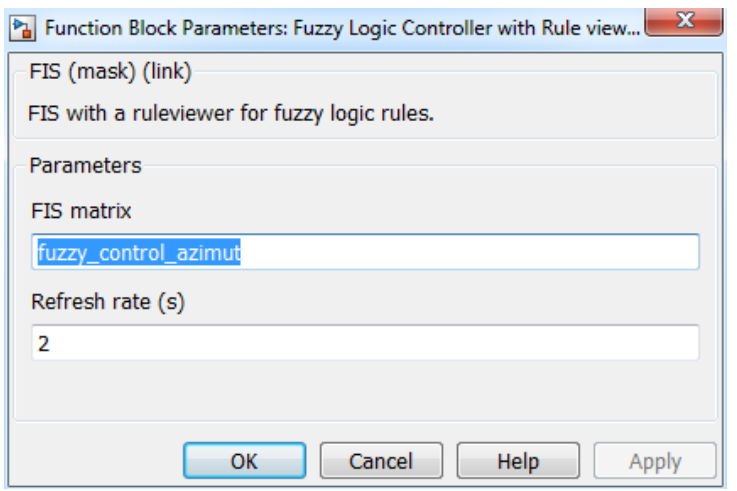

(b) function blok parameter for defining FIS file

Fig. 12. Fuzzy logic controller for azimuth rotation.

\section{EXPERMENTAL RESULTS}

In this research, Matlab/simulink software is used to experiment of the PID controller and fuzzy logic controller application for a prototype of gun-turret system. We will compare between the experimental result performaces of PID controller and fuzzy logic controller with seven rules.

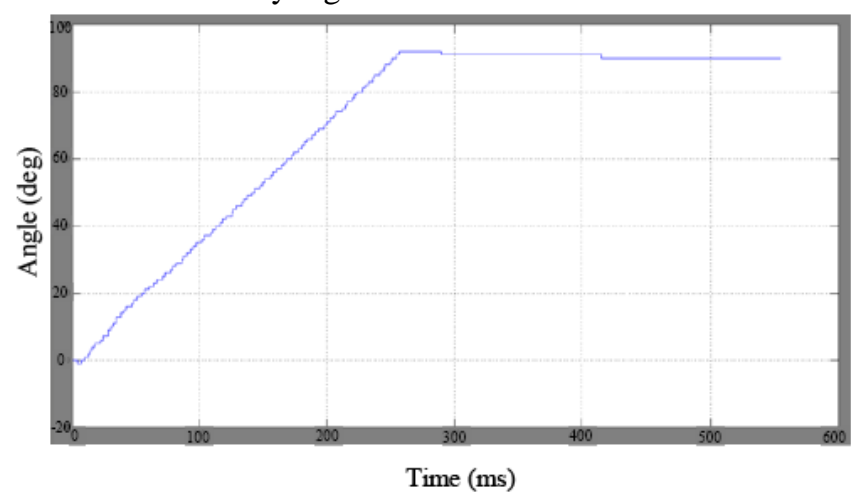

(a) Response system by setpoint $90^{\circ}$

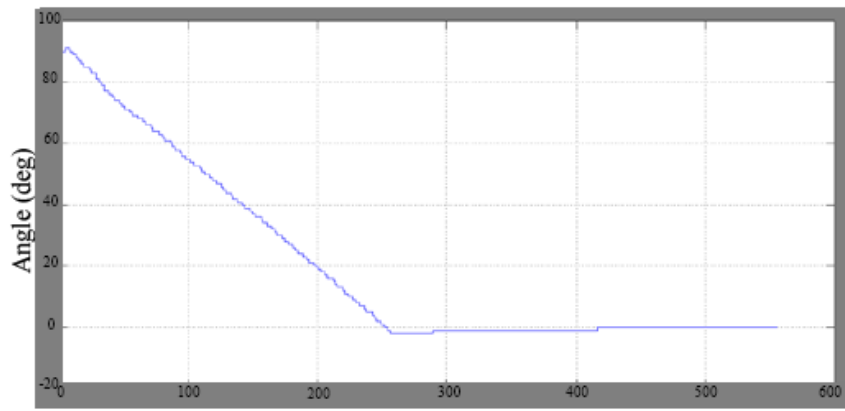

Time (ms)

(b) Position error

Fig. 13. Response system and position error of PID controller for the azimuth rotation.

Both PID controller and fuzzy logic controller have to control the azimuth rotation's angle of base and elevation movement's angle of barrel. We set the azimuth rotation's angle by setpoint $90^{\circ}$, and the elevation movement's angle of barrel by setpoint $35^{\circ}$. The Fig. 13 (a) shows the response 
system and (b) shows the position error that is resulted by PID controller for the azimuth rotation. We use the PID gain as ilustrated in Fig. 6 (b), in which the value of each $\mathrm{Kp}, \mathrm{Ki}$, and $\mathrm{Kd}$ are 85, 0,5, and 1 respectively.

The experimental results of elevation movement's angle of barrel is set by $35^{\circ}$ and we use the PID gain presented in Fig. 7 (b) in which $\mathrm{Kp}, \mathrm{Ki}$, and $\mathrm{Kd}$ are 14, 0,1, and 1. For this second experiment of PID controller, we deliberately choose a high gain of Kp for occurring the overshooting response system. This experimental results are presented in Fig. 14.

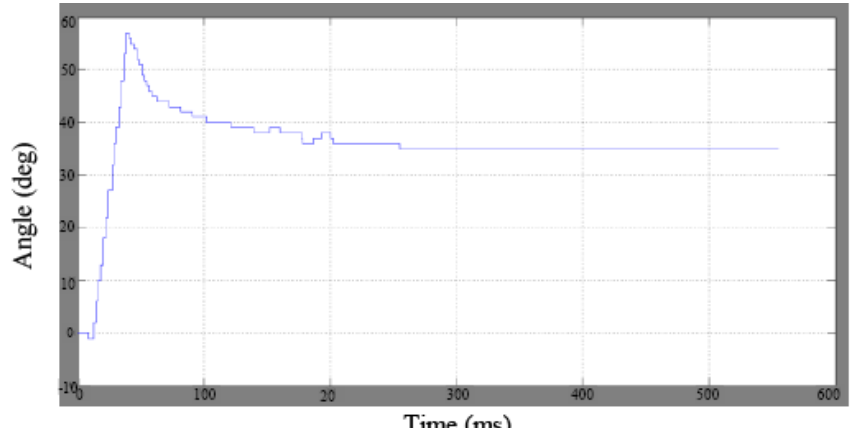

(a) Response system by setpoint $35^{\circ}$

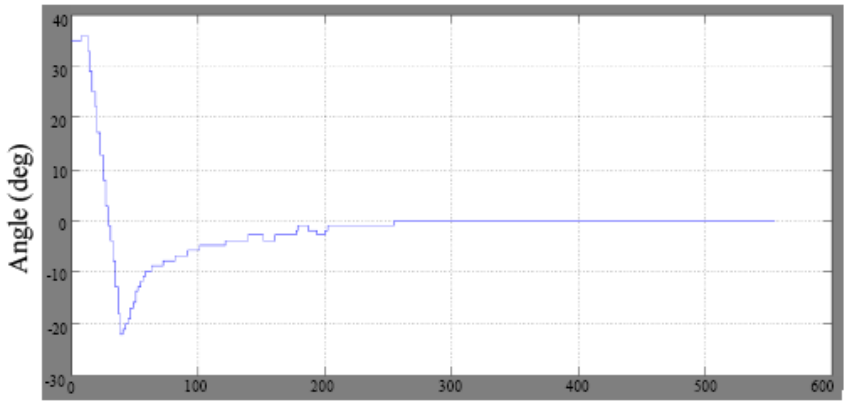

Time (ms)

(b) Position error

Fig. 14. Response system and position error of PID controller for the elevation movement.

Further, we will present the experimental results using fuzzy logic controller. Setpoint of angle are same value as defined in the PID controller. The Fig. 15 (a) shows rule viewer of the azimuth rotation, and (b) shows the response system that is resulted by the fuzzy logic controller. Then, the experimental results for the elevation movement of barrel are presented in Fig. 16, in which (a) describes the rule viewer, and (b) presents the response syst. em

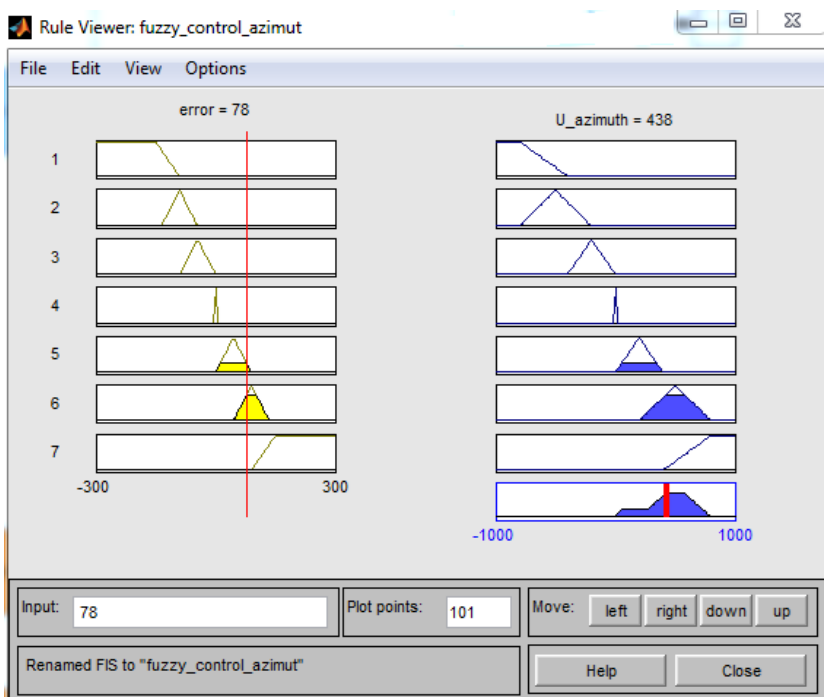

(a) Rule viewer process

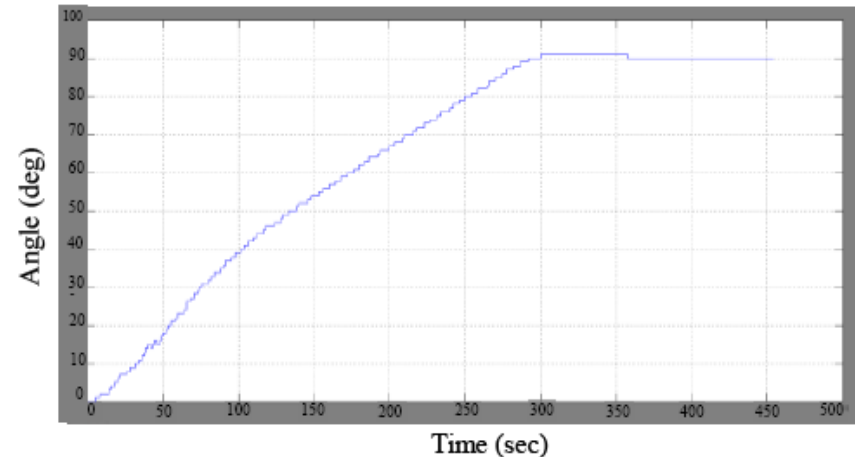

(b) Response system

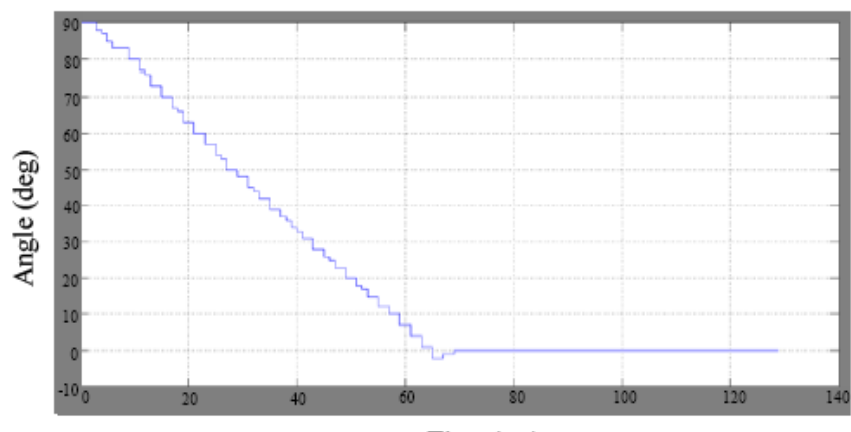

Time (ms)

(c) Position error

Fig. 15. Rule viewer, response system, and position error of the azimuth rotation.

Both PID controller and fuzzy logic controller have been implemented on the prototype of gun-turret system. The experimental results from the comparison of PID controller and fuzzy logic controller techniques show that fuzzy logic is better than PID controller, it is based on Fig. 13-16. When the fuzzy logic controller is used to control azimuth rotation that is shown by Fig. 15 (b), it is faster to acieve the setpoint value than the PID controler that is shown by Fig. 13 (a). Similar result for control elevation movement, in which the fuzzy logic controller (Fig. 16 (b)) is also faster than the PID controller (Fig. 14 (a)) for converging to setpoint value. The fuzzy logic controller can reduce the effects of nonlinearity in a DC motor. On the other hand, fuzzy logic controller seems to accomplish better control quality with less complexity (if tuning or gain scheduling is needed for the PID approach).

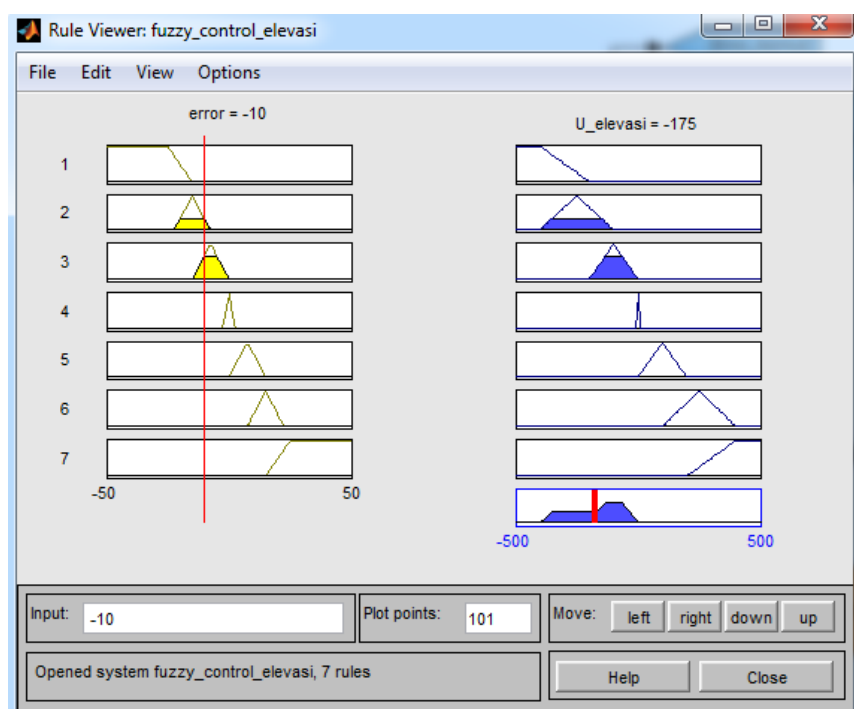

(a) Rule viewer process 


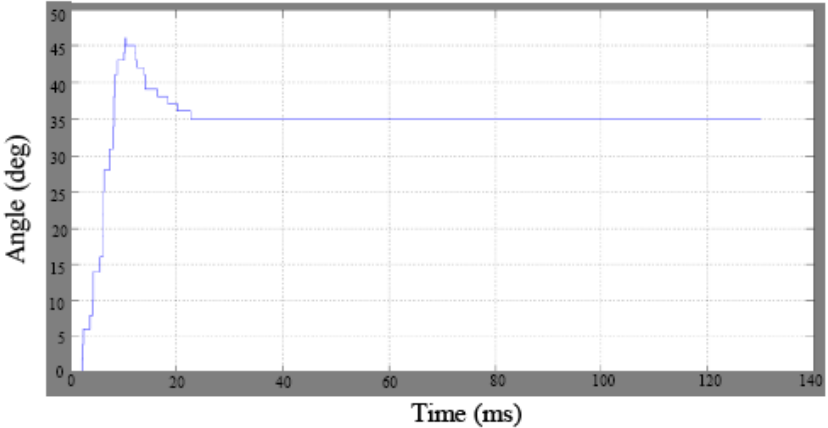

(a) Response system

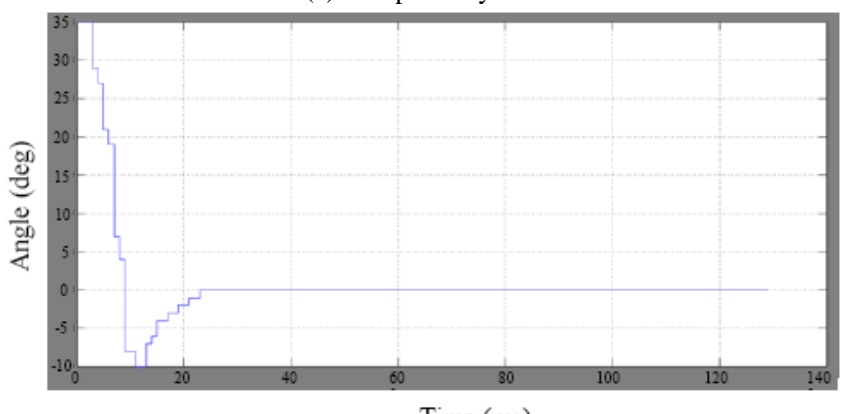

(b) Position error

Fig. 16. Rule viewer, response system, and position error of the elevation movement of barrel.

\section{CONCLUSIONS}

We have studied a solution to control of two DC motor that are used on the prototype of gun-turret systems using PID controller and fuzzy logic controller. Both controllers are implemented using Matlab/simulink, and the implementation procedure of fuzzy logic controller is presented in Matlab/Simulink using fuzzy logic toolbox to execute the control of gun-turret system by definning seven rules. Based on experimental results, response systems with les overshoot and minimum setting time that resulted by fuzzy logic controller is better than PID controller. The fuzzy logic controller gets on to achieve a rapid and precise position tracking performance.

\section{ACKNOWLEDGMENT}

This work was financially supported by Implementing Indonesia's Economic Master Plan (MPEI) for Research Grand No. : 253/SP2H/PL/DIT.LITABMAS/VII/2013 from Directorate General of Higher Education, Ministry of National Education, Indonesia.

\section{REFERENCES}

[1] J. Y. Hung, W. Gao, and J. C. Hung, "Variable structure control: A survei," IEEE Transactions Industrial Electronics, vol. 40, no. 1, pp. 2-22, Feb. 1993.

[2] Munadi and T. Naniwa, "An adaptive controller dominant-type hybrid adaptive and learning controller for trajectory tracking of robot manipulators," Advanced Robotics, vol. 26, no. 1-2, pp. 45-61, Jan. 2012.

[3] L. Feng, X. Ma, Z. Yan, and H. Li, "Method of adaptive fuzzy sliding mode control of gun control system of tank," Electric Machines and Control, vol. 11, no. 1, pp. 65-69, Jan. 2007.

[4] F. L. Lewis, D. M. Dawson, J. Lin, and K. Liu, "Tank gun-pointing control with barrel flexibility effects," in Proc. Winter Annual Meeting of the American Society of Mechanical Engineers, ASME Dynamic System and Control Division, Atlanta, 1991, pp. 65-69.

[5] G. Kumar, P. Y. Tiwari, V. Marcopoli, and V. Kathare, "A study of a gun-turret assembly in an armored tank using model predictive control," in Proc. 2009 American Control Conference, Missouri, 2009, pp. 4848-4853.

[6] M. D. S. Gomes and A. M. Ferreira, "Gun-turret modelling and control," in Proc. ABCM Symposium Series in Mechatronics, Ouro Preto, 2006, pp. 60-67.

[7] L. A. Zadeh, "Fuzzy sets," Information and Control, vol. 8, pp. 338-353, June 1965.

[8] E. H. Mamdani, "Application of fuzzy algorithms for control of simple dynamic plant," the Institution of Electrical Engineers, London, 1974 pp. 1585-1588.

[9] S. K. Das and P. Dibyendu, "Formulation of FISPLAN: A fuzzy logic based reactive planner for AUVs towards situation aware control," International Journal of Intelleigent Systems and Applications, vol. 5 , no. 9, pp. 47-57, August 2013.

[10] W. A. Zhen and R. G. Feng, "The design of neural network fuzzy controller in washing machine," in Proc. 2012 International Conference on Computing, Measurement, Control and Sensor Network (CMCSN), Shanxi, China, 2012, pp. 136-139.

[11] J. H. Kim, K. C. Kim, and E. K. P. Chong, "Fuzzy Precompensated PID Controllers," IEEE Trans. On Control Systems Technology, vol. 2, no. 4, pp. 406-411, Dec. 1994

[12] M. Galal, N. G. Mikhail, and G. Elnashar, "Fuzzy logic controller design for gun-turret system," in Proc. 13th International Conference on Aerospace Sciences \& Aviation Technology, Cairo, 2009, pp. 1-12.

[13] B. Mrozek and Z. Mrozek, "Modelling and fuzzy control of DC drive," in Proc. 14th European Simulation Multiconference ESM 2000, Prague, 2000, pp. 186-190.

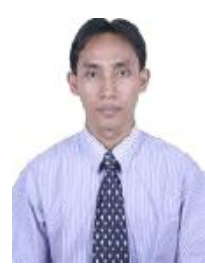

Munadi received his B.E. degree in the Dept. of Mechanical Engineering at Diponegoro University in 2001, and M.E. degree in the Dept. of Mechanical Engineering, Bandung Institute Technology in 2007, Indonesia and he received his D.E. degree in the Dept. of Human and Artificial Intelligence Systems at University of Fukui in 2011, Japan. He worked as a maintenance engineer from 2001 to 2005 at Pura Group Corp. From 2005, he was as a lecturer at the Department of Mechanical Engineering of Diponegoro University, Indonesia. His research interests are hybrid adaptive, learning controller of robotics and automation systems.

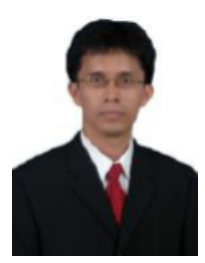

Joga Dharma Setiawan received his B.Sc degree in Mechanical Engineering from Northeastern University, USA in 1992; and the M.Sc. degree in Aeronautics/Astronautics from Massachusetts Institute of Technology, USA in 1996. He received the Ph.D degree in Mechanical Engineering from Michigan State University, USA in 2001. He worked as a research and development engineer at Beacon Power Corporation in Massachussetts, USA from 2001 to 2003 . He is currently a lecturer in the Mechanical Engineering Department of Diponegoro University, Indonesia. His research interests include dynamics and control of mechanical systems.

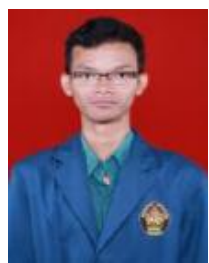

Muhammad Fairuz Luthfa was graduated from Semesta High School Semarang in 2009. He was born in Kudus, $22^{\text {nd }}$ of September 1990. He is a student in Diponegoro University, Indonesia. He takes electrical engineering as a major field study and control engineering as a minor field study. His research interests are embedded systems, robotics and automation systems. 